\title{
La casa-patio de entramado de madera: construcción, transformación y rehabilitación de casas particulares, posadas y edificios de vivienda colectiva en Madrid
}

\author{
Timber-framed courtyard buildings: construction, transformation and \\ conservation of Houses, Inns and Collective courtyard buildings
}

\author{
Esperanza González-Redondo ${ }^{(*)}$
}

\section{RESUMEN}

La casa-patio de entramado de madera, con galerías y cuartos perimetrales, es de gran interés constructivo pero complejo análisis. En Madrid, numerosas casas particulares, posadas y casas-patio colectivas, de obligada conservación (PGOUM,1997), no constan como nuevas construcciones (1494-1868). El descubrimiento de una 'casa a la malicia', que ocultaba una posada con 'aposentillos' formando un patio interior; y su posterior ampliación con otra crujía con corredor (1737), situará la transformación de las casas particulares de los arrabales en una nueva tipología, la casa-patio colectiva con cuartos de alquiler. Existirá una fase intermedia, la casa-patio de transición, de parámetros específicos. El análisis constructivo de proyectos antiguos con información en planta (17241788), fachadas de innumerables casas-patio conservadas o demolidas (1656-1868), y su levantamiento planimétrico, determinarán un modelo repetido denominado casa de vecinos y recientemente corrala. Tiene sectores estructuralmente diferenciables, viviendas-tipo en fachada y mínimas alrededor del patio, corredores, letrinas comunitarias y pozo.

Palabras clave: Casa-patio; estructuras de entramado de madera; patrimonio arquitectónico; posada; corrala; vivienda colectiva; rehabilitación; Madrid.

\section{ABSTRACT}

The historic courtyard house type, with wooden galleries and perimeter rooms, is of great constructive interest, but complex analysis. In Madrid, numerous houses, inns, and collective courtyard buildings, of obligatory conservation (PGOUM, 1997), are not registered as new constructions (1494-1868). The discovery of a hidden inn (1737), with small rooms in the yard, the result of the expansion of existing construction, will place the transformation of the private houses of the suburbs into a new typology, the 'collective courtyard building' with rooms for rent. There will be an intermediate phase, the 'transitional courtyard house', with specific parameters. The constructive analysis of old projects with information on the plan (1737-1788), facades of countless preserved or demolished (1724-1905), and the planimetric survey of some singular courtyard houses, will determine a later repeated model called a 'house of neighbours' and recently 'corrala'. It has structurally differentiable sectors, type dwellings on the façade and minimal around the courtyard, with a well, corridors and community latrines.

Keywords: Courtyard house; timber-framed structures; architectural heritage; inn; corrala; collective buildings; rehabilitation; Madrid.

(*) Dra. Arquitecta. Profesora Titular de Universidad. Universidad de Alcalá, Madrid (España).

Persona de contacto: esperanza.gonzalez@uah.es (E. González-Redondo)

ORCID: http://orcid.org/oooo-ooo1-6481-3578 (E. González-Redondo)

Cómo citar este artículo/Citation: Esperanza González-Redondo (2021). La casa-patio de entramado de madera: construcción, transformación y rehabilitación de casas particulares, posadas y edificios de vivienda colectiva en Madrid. Informes de la Construcción, 73(563): e403. https://doi. org/10.3989/ic.80512

Copyright: (C) 2021 CSIC. Este es un artículo de acceso abierto distribuido bajo los términos de la licencia de uso y distribución Creative Commons Reconocimiento 4.0 Internacional (CC BY 4.0). 


\section{INTRODUCCIÓN}

Las casas de las ciudades históricas, de estrecha fachada y largo fondo, y cuyos solares entre medianeras están completamente edificados, requieren de la construcción de patios en las crujías interiores. No obstante, existen diferencias constructivas entre el término casa con patio, necesario para la iluminación y ventilación, y el concepto de casa-patio que tiene además un pasillo de distribución en el patio. Tradicionalmente, esta tipología de vivienda particular con galería, o casa-patio de poca altura y entre medianeras, tuvo soluciones constructivas diversas (1).

Algunas posadas siguieron este modelo, y situaron las habitaciones de hospedaje alrededor de un patio interior. Está poco documentado si eran antiguas casas particulares ampliadas con nuevas crujías en el corral, como la Posada del Potro en Córdoba, o edificios proyectados con ese objetivo. Algunos edificios de vivienda colectiva entre medianeras también se ajustaron al tipo de casa-patio, como las insulae o casas urbanas de alquiler en Roma, resultado de la transformación, elevación y agrupación de las casas de atrio (1). En América latina también se extendieron los edificios con pequeñas viviendas alrededor de un patio, entre otros, 'conventillos' (2) e 'inquilinatos' (3).

Estas casas-patio colectivas también se construyeron en Aranjuez, Chinchón y Alcalá, entre otros lugares; y la literatura, siendo ya un modelo de facto consolidado, las etiquetó en Madrid como 'casas de vecinos'. Antiguas o modernas, no se conocen escritos rigurosos o detalles en planta que puedan demostrar el origen de estas casas-patio y sus pequeñas viviendas.

Algunos estudios documentan la construcción de casas particulares en Madrid en los siglos XVII y XVIII (4), y el uso de sus estructuras de entramado de madera desde 1555 (5). Los maderos utilizados se regularon posteriormente (Ardemans, 1719) (6); y los diccionarios son los primeros textos que recogen los términos asignados a estas estructuras: RAE (1780); Silva, (1788) ; Bails (1802); y Matallana (1848). A continuación, libros técnicos de relevancia incluyeron detalles constructivos, Marcos y Bausá (1879) (7), Ger y Lóbez (1898) (8), y Gaztelu (1898) (9). Actualmente, el término más aceptado para describir a esta tipología de casa-patio colectiva de entramado de madera es casa de corredor o corrala; entre otros, Boden (1977) (10) y Sánchez, M. (1979) (11); y nuevamente, Berlinches, A. (2003) (12), Santa Cruz, J. (2012) (13), Fernández (2017) (14) y González, E. (2018) (15). Sin embargo, teniendo en cuenta que su construcción comenzó al menos 200 años antes, la acuñación de este término es reciente (16).

En el Centro histórico de Madrid, ocultas desde el exterior y apenas conocidas, perviven numerosas casas-patio consideradas antiguas; entre ellas, algunas posadas, palacios, casas particulares y unos 400 edificios de vivienda colectiva (figs. 1 y 2). El valor de este patrimonio arquitectónico conservado fue reconocido por primera vez en los años 1980 (17). En 1997, el Catálogo de elementos protegidos del Plan General de Ordenación Urbana de Madrid (PGOUM) estableció la obligación de conservarlos, frenando así su incesante demolición (18).

Trabajos recientes demuestran que muchos casos conservados, externamente homogéneos, presentan discordancias en planta y sección. También concluyen que la construcción de estas casas-patio, demolidas o conservadas, apenas están detalladas en los archivos (16) y (19). En este punto, y teniendo en cuenta que el Archivo de la Villa de Madrid se creó en 1602

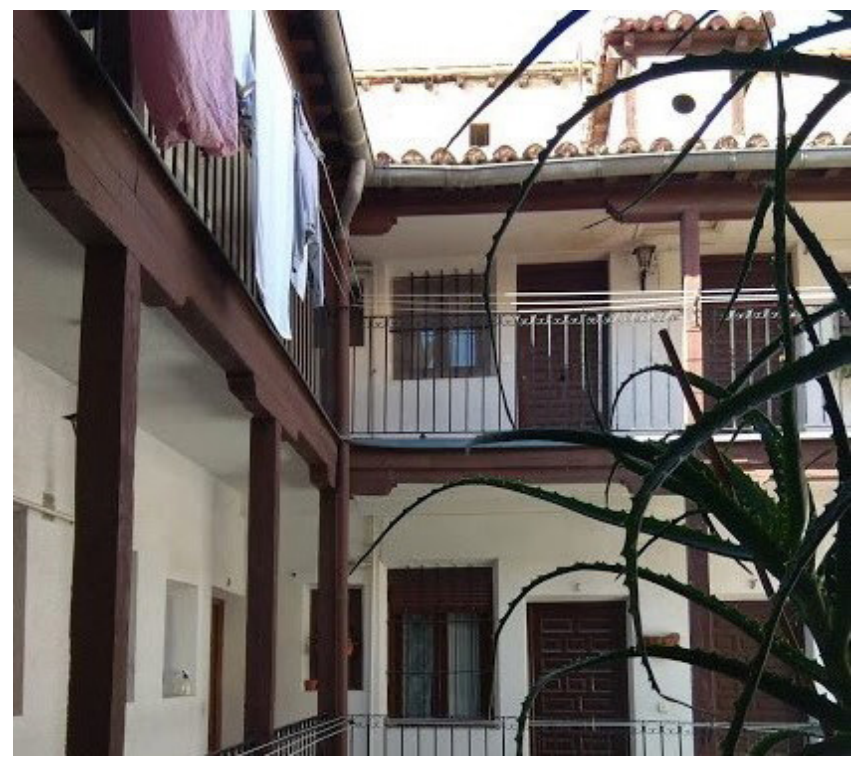

Figura. 1. Casa-patio colectiva, Barco 33 (Arrabal del Norte).

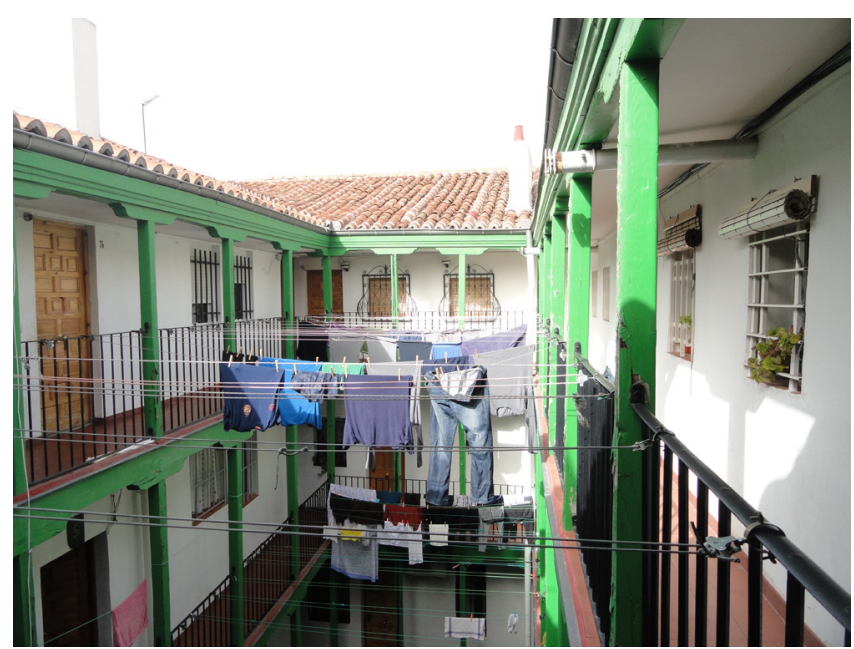

Figura. 2. Casa-patio colectiva, Salitre 34 (Arrabal del Sur).

y que, desde la primeras Ordenanzas en Madrid (Torija, 1641; y Ardemans, 1731) (6), los edificios de nueva construcción debían solicitar licencia de obras, se formulan los siguientes interrogantes:

1. ¿Por qué no hay documentación?

2. ¿Dónde se localizan estos tipos de casas-patio?

3. ¿Cuándo comenzó su construcción?

4. Respecto a su uso original: ¿eran casas particulares, Posadas o edificios de vivienda colectiva?

5. ¿Es similar la construcción de todos ellos o tienen elementos específicos de cada tipo?

6. Si no están registrados como nueva construcción ¿Son el resultado de la transformación de edificios ya existentes?

\section{OBJETIVOS}

Este artículo recoge los últimos avances de un ambicioso proyecto de investigación desarrollado en distintas etapas, (2000-2004) y recientemente (2014-2020) (20). Su objetivo es la datación y el análisis constructivo de las casas antiguas conservadas en el Centro histórico de Madrid o dentro de la Cerca de Felipe IV (fig. 3). Más de 30.000 están incluidas en el Catálogo del PGOUM (17) y, entre ellas, son singulares las que 
tienen solución constructiva de casa-patio. El reto es sacar a la luz las fuentes documentales más antiguas en las que esta tipología quede registrada de forma gráfica o escrita, para cotejar los resultados con los edificios conservados, y así resolver los interrogantes de partida. En concreto, se pretende:

1. Establecer las diferencias constructivas entre los conceptos 'casa con patio' y 'casa-patio', y sus variantes: a) Casa particular; b) Casa posada; y c) Casa colectiva.

2. Determinar los tipos de alojamiento: a) alojamiento de viajeros en habitaciones en torno a un patio en la Posada; y b) alojamiento para familias en la casa-patio colectiva.

3. Análisis constructivo de proyectos originales, fijando: a) la configuración del patio y los sectores; b) dimensionado de elementos estructurales, crujías y muros de carga; y c) estudio de superficies y distribución interior: los 'cuartos' o 'habitaciones' del sector frontal y del trasero.

4. Catalogar las casas-patio colectivas aún indocumentadas: levantamiento planimétrico, y conjetura sobre su construcción original.

5. Introducir el concepto 'casa de transición', o aquella que proviene de la ampliación y rehabilitación de una construcción existente, determinando los parámetros de transición.

6. Partiendo de las 'casas a la malicia' (19), y del descubrimiento de una posada en c/ Magdalena (1737), inventariar otras 'posadas a la malicia', estableciendo el inicio de la construcción en serie.

7. Instaurar la cronología, localización y extensión de un nuevo modelo, la casa-patio colectiva, como resultado de construir 'cuartos de alquiler' de dimensiones mínimas.

\section{METODOLOGÍA Y FASES DEL ANÁLISIS}

Los últimos resultados son fruto de una nueva búsqueda realizada en el Archivo Histórico de la Villa (AVM), el Archivo Histórico del COAM, el Archivo Histórico de Protocolos de Madrid (AHPM) y el Archivo de la Empresa Municipal de la Vivienda (EMV). Tras el estudio de innumerables memorias de solicitud de licencia de obras y la comparación con los edificios conservados, los logros de la investigación son: a) la identificación de unos 15 proyectos antiguos (1737-1768) con información gráfica en planta (tabla 1); b) la comprobación de un gran número de casos demolidos; y c) la datación de las fachadas de unas 40 casas-patio conservadas (1777-1868) (21) y (tabla 2).

La fase inicial recoge información sobre las casas más antiguas documentadas con descripción gráfica de sus patios, corrales o jardines. Sus resultados han conducido al hallazgo de expedientes inéditos de antiguas Posadas y Casas-patio colectivas, que documentarán por primera vez el origen de estas construcciones (21).

En paralelo se desarrolla el trabajo de campo, clasificando y detallando una selección de casas-patio conservadas. También, se indaga sobre la construcción con estructuras de entramado de madera, muros de carga, forjados y cubiertas (6), (9), (10) y (14). A continuación, se revisarán en detalle aquellos registros que incorporan el término Posada, Casa para 'alquiler de cuartos' u otro, y no sólo Construcción de casa.
Se estudia la Planimetría de Madrid (1632-1997) (figs. 3 y 4) aplicando los resultados obtenidos a edificios concretos que servirán de modelo. Así mismo, se establecerá la cronología de los casos documentados, antes y después de la Real Provisión de 1788, determinando su efecto o impacto en la construcción de este modelo y sus variantes. Se comprobará que gran parte de las casas-patio registradas en 1860 y (1872-74) han desaparecido, siendo sustituidas por edificios modernos (17).

Finalmente, se evidenciará la coincidencia o no de la información contenida en la documentación de archivo con el levantamiento planimétrico de los edificios conservados, con atención prioritaria a las discordancias de los sectores. Los planos de detalle de casas antiguas y modernas justificarán una vez más la complejidad del análisis constructivo del sector trasero con su patio y, por tanto, de esta investigación.

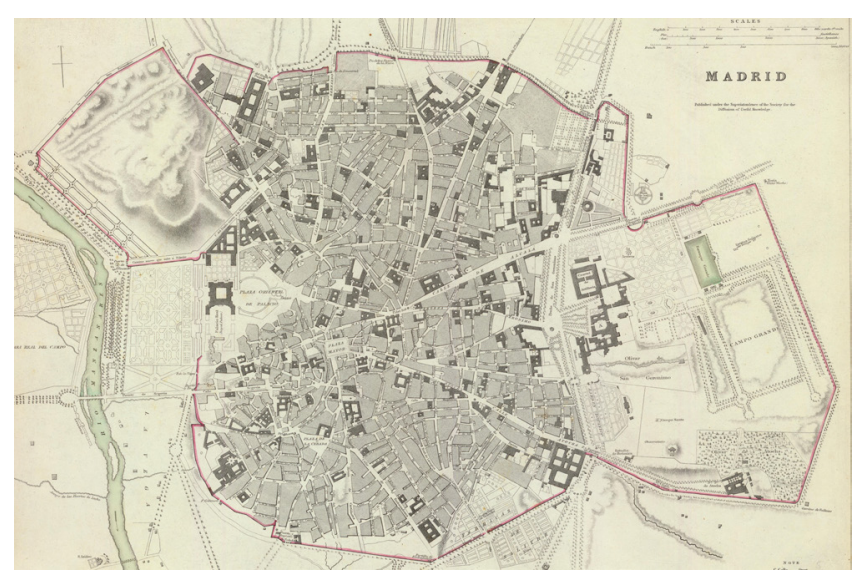

Figura 3. El Centro histórico de Madrid, y la muralla (1831).

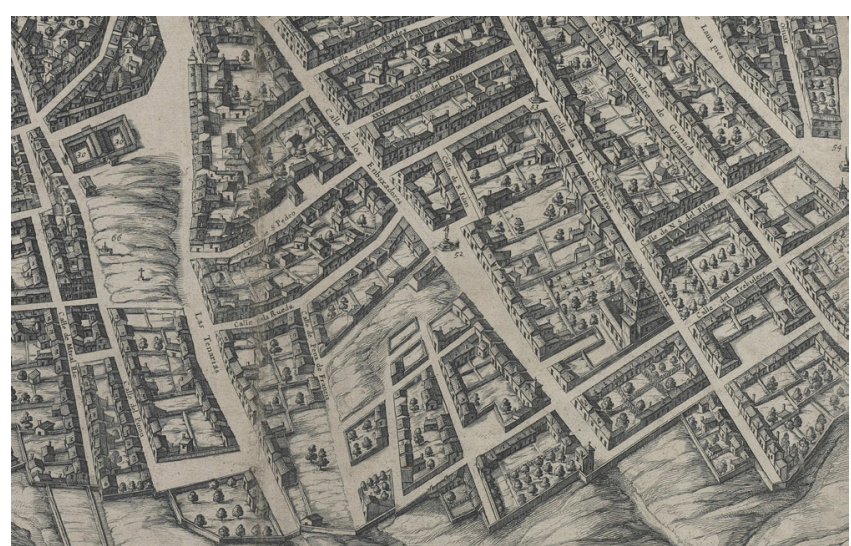

Figura 4. El Arrabal del sur y la Cerca de Felipe IV (Texeira, 1656).

\section{LA CASA-PATIO EN MADRID: ANÁLISIS CONS- TRUCTIVO Y PARÁMETROS DE ESTUDIO}

La búsqueda de documentos originales, con el fin de identificar casas antiguas de entramado de madera con patios y corredores, ha resultado complejo. Son pocos los expedientes con información gráfica en planta y las secciones casi inexistentes. Por otro lado, la comprobación de estos registros con los edificios catalogados (17), confirma que: a) los expedientes más antiguos (a. 1765) se corresponden con edificios demolidos; b) muchos edificios conservados (fig. 6) y considerados antiguos no tienen su correspondiente expediente; y c) algunos aparentemente modernos (1847-1874), son antiguos con plantas añadidas en fecha posterior a su construcción original (21). 
Sin embargo, la búsqueda de información gráfica de antiguas Posadas ha dado grandes resultados. Se detecta que algunas, conservadas o desaparecidas, responden a la tipología constructiva de casa-patio. Especialmente, se ha descubierto el primer edificio con vocación de construcción en serie (1737), donde se repite intencionadamente un módulo, o 'cuartos de una pieza', convirtiéndose en el hilo conductor de este artículo. Su análisis constructivo situará la transformación de las casas particulares de los arrabales en un nuevo tipo, la 'casa-patio colectiva', con una fase intermedia, la ‘casa-patio de transición'.

\subsection{Casas particulares, posadas y edificios de vivien- da colectiva para 'alquiler de cuartos'}

Según consta en los expedientes de solicitud de licencia de obras del Archivo de la Villa, todas las 'casas', se consideraban Obras particulares: las de uso del propietario, las posadas, y las destinadas al alquiler (21). Las particulares, tenían una sala y la cochera con fachada a la calle y en el fondo, el patio, la cuadra y el pajar. En la planta superior estaba la vivienda con las salas principales, un corredor y una zona de servicio; y en el bajo cubierta se alojaban los criados.

Las Casas-posada, con el indicador de 'Posada' en su puerta, servían de hospedaje. En planta baja situaban la taberna, una gran chimenea o cocina, un patio con pozo, caballerizas, pajar, y una escalera de acceso al corredor de distribución de las habitaciones en plantas superiores. Las más antiguas conservadas son la Posada del Peine (1621) y la Posada de la Villa (1642). Sin embargo, los casos más singulares, dada la configuración de su patio con una galería de madera en su perímetro, son posteriores (1724-1878) (21).

Las casas para 'alquiler de cuartos' o 'habitaciones' tenían un propietario y diversos inquilinos. Este modelo de edificio destinado al alquiler, aún vigente, se extendió tanto para la ampliación de las casas existentes como para las de nueva construcción (19). Se detectan dos tipos: a) $\mathrm{Ca}$ -
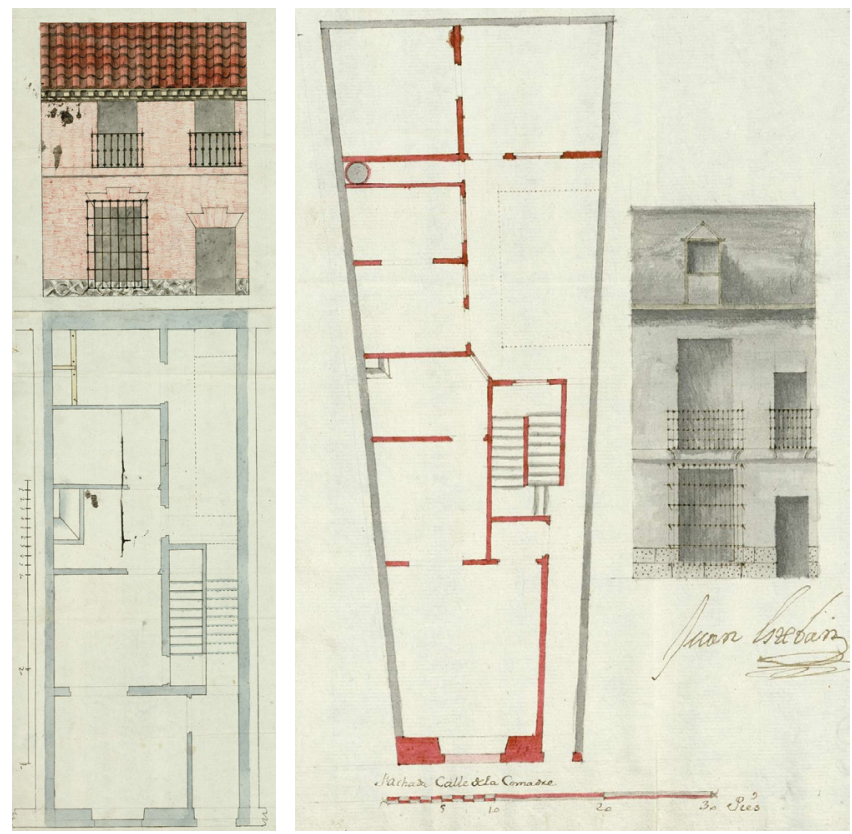

Figura 5. a) Casa-patio particular c/Gobernador (1694, AVM: 1-66109); b) casa-patio colectiva c/Amparo (1751, AVM: 1-84-148).

sas sin sectores diferenciables y con patios residuales para iluminación y ventilación; y b) Casas con 2 sectores reconocibles, frontal y trasero, siendo la casa-patio colectiva un caso particular. Según se comprueba, responde a una tipología proyectada intencionadamente para instalar el mayor número posible de unidades mínimas de vivienda ocupando todo el solar y desapareciendo, por tanto, el corral o jardín trasero.

En síntesis, todas las casas-patio mencionadas comparten dos características esenciales: una organización constructiva principal a base de crujías paralelas al muro de fachada, de mayor espesor que los demás, y no siempre con distribución rítmica de huecos y balcones; y otra secundaria

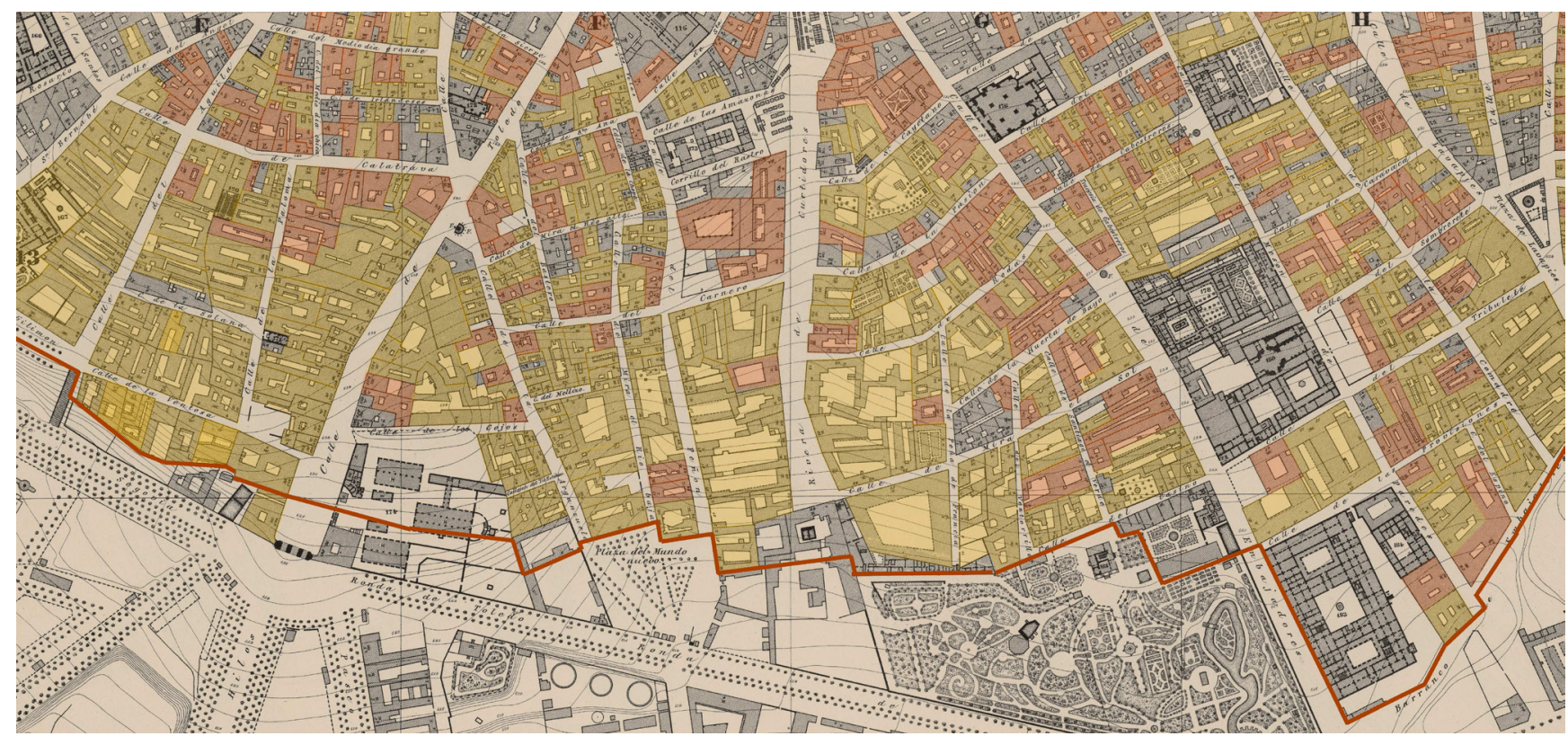

Figura 6. Construcción, conservación y demolición de casas-patio en el 'arrabal sur’ (Ibáñez Ibero, 1872-74). Cerca de Felipe IV demolida en 1868 (marrón); Casas-patio demolidas (amarillo); casas-patio conservadas (bronce). (Autor, 2020). 
a partir de la $3^{\mathrm{a}}$ o $4^{\mathrm{a}}$ crujía, con cambio en la dirección del forjado, y un patio interior con una galería (fig. 5). Desde ésta se accede a las habitaciones en las Posadas, las salas en las viviendas particulares (fig. 5a) (22) y los 'cuartos de alquiler' en las casas-patio colectivas (fig. 5b) (23). Sin embargo, un análisis detallado fija otros indicadores: a) la mayor parte de las casas-patio antiguas tienen poca altura y el corredor en voladizo; b) Las posadas tienen una puerta y zaguán grandes, y habitaciones a partir de la planta principal; c) la casa-patio colectiva, en cambio, tiene una puerta de acceso pequeña y todas sus plantas destinadas a habitaciones (21); y d) algunos ejemplos tienen los sectores, frontal y trasero, estructuralmente diferenciables (19).

El análisis desarrollado a continuación determinará las características de cada tipo, incluyendo ejemplos de casas desaparecidas y conservadas (fig. 6). Entre éstas, no sólo las catalogadas con protección Integral o Estructural, sino también Parcial o Ambiental (17), en caso de considerarse antiguas. El conflicto reside en la falta de documentación del sector trasero, de ahí la búsqueda de nuevos parámetros 'in situ': a) el acceso al patio en los distintos tipos; b) la existencia de sectores estructuralmente diferenciados; c) las medidas de la $1^{\mathrm{a}}$ y $2^{\mathrm{o}}$ crujía; d) el cambio en la dirección del forjado en el patio; e) las crujías asimétricas; e) el espesor del muro del sector frontal con fachada al patio; $y$ f) la repetición intencionada de un patrón o construcción 'en serie', y sus dimensiones.

\section{LA CASA PARTICULAR}

La principal información acerca de pequeñas construcciones privadas con dos crujías y corral, jardín o huerto trasero, es la dibujada en el Texeira, 1656 (fig. 4). Se advierte que la ocupación de las parcelas y la altura del Centro era mucho mayor que en la muralla. Pocos expedientes (1495-1656) incorporan información en planta $\mathrm{y}$, aunque algunos registros de casas en los 'arrabales' todavía dibujan un espacio residual trasero (1746-1771), la tendencia de los edificios de nueva construcción es a ocupar progresivamente todo el solar (21). Un caso singular, dada su antigüedad, y porque muchas pequeñas viviendas seguirán este modelo, es Gobernador (1694) (fig. 5a) (22), tiene 2 alturas, una vivienda con 5 piezas en cada planta, y un patio en un lateral con corredor en voladizo. Casos posteriores similares son, Plaza S. Esteban (1741) y Olivar (1745) (21). Por otro lado, las casas con 3 o 4 huecos en fachada tienen mayores dimensiones y un patio a un lado, Infantas (1771) (fig. 7) (24); o centrado, Infantas c/v Capuchinas (1769) (fig. 8) (25).

No existe un modelo fijo, ni un módulo que se repita, aunque las parcelas más comunes presentan un frente de fachada con 2 o 3 líneas de huecos, construyen todo el solar y tienen una vivienda por planta (figs. 5, 7 y 8). En el sector frontal destaca la fachada con una puerta enmarcada en ladrillo o piedra que por un pasillo estrecho da acceso a la escalera, y a un patio, algunas con cuadra y pajar. En la $1^{\text {a }}$ crujía $\left(3.5^{-4.5} \mathrm{~m}\right)$, se ubicaban las salas principales, y en la $2^{\text {a }}$ las alcobas. En el sector trasero, con muros de carga perpendiculares a los del sector frontal, y forjados apoyando en medianeras y patios, se ubican las salas de servicio: alcobas, cocina, despensa y cuartos de criados. Para su distribución, con fondos de parcela habituales de 20-30m y patios amplios, prolongan el forjado con corredores de madera.
Una primera diferencia es que la casa-patio tiene una galería exterior para el acceso a las salas de servicio (figs. 5, 7 y 8), y las casas con patio tienen un pasillo interior (21). La jerarquía funcional de ambos sectores no siempre lleva asociada una jerarquía estructural con muros de carga de distinto espesor.

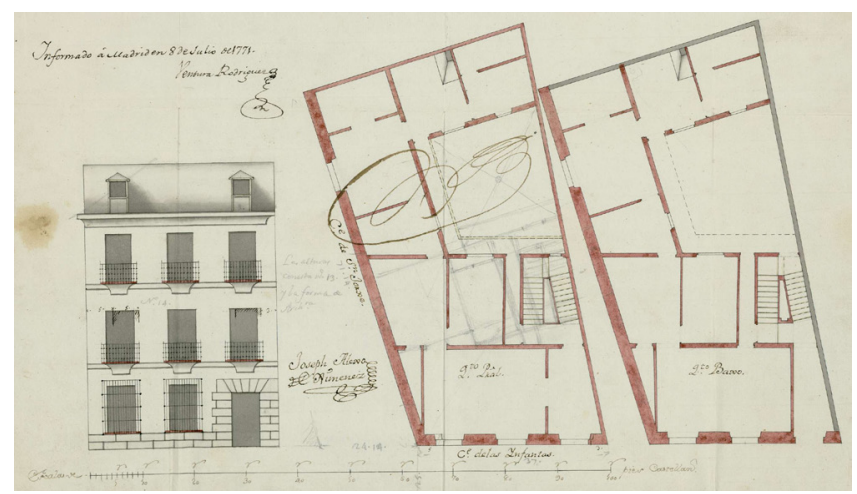

Figura 7. Casa-patio particular en c/Infantas (1771, 1-46-76).

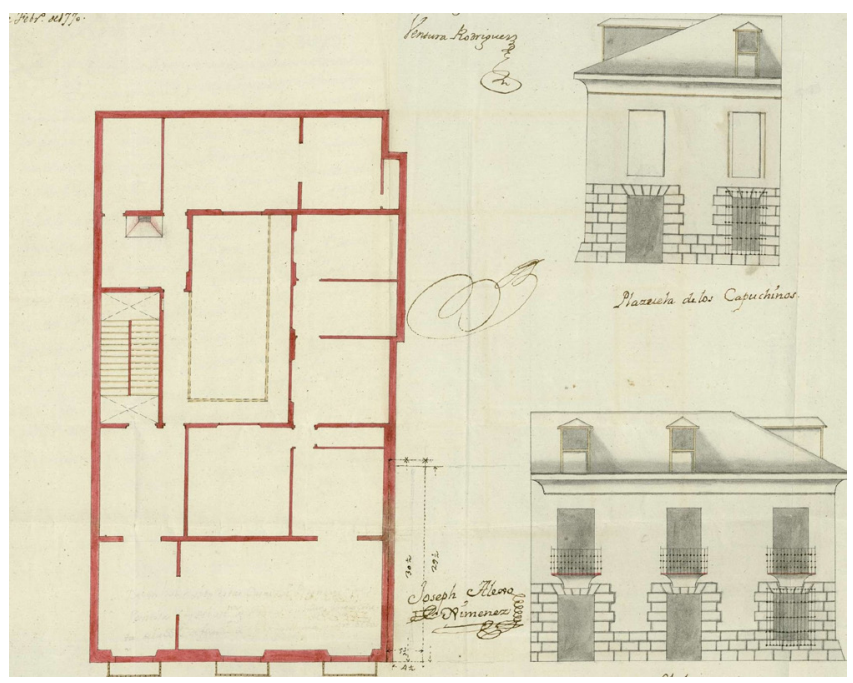

Figura 8. Casa-patio particular en c/Capuchinas (1769, AVM 1-47-18).

\section{LA CASA-POSADA}

Las posadas se situaban cerca de las puertas de entrada a la ciudad. Las más antiguas se ubicaron junto al recinto medieval, actual Cerca y Arrabal de Felipe II (figs. 9 y 10), y las modernas próximas a la Cerca de Felipe $I V$, área denominada Conjunto Monumental (17) (fig. 3). Al igual que las casas-patio descritas anteriormente, se construyeron en todo tipo de solares, prevaleciendo los rectangulares de fachada estrecha y largo fondo. La dificultad del estudio reside nuevamente en la falta de documentación del sector trasero, asumiendo que tenían cuartos o habitaciones alrededor de un patio con corredor.

La información gráfica del alzado, datados ya más de 40 edificios en el proyecto (5), (16) y (19); y tablas 1 y 2 da como elemento clave distintivo de la Posada la amplitud de su puerta y zaguán para el acceso de los carros y caballos hasta el patio. Entre estos casos se encuentran las antiguas documentadas: Posada del Peine (1654) y Posada de la Cava Baja (1724) (fig. 9) (26); las indocumentadas, Posada El león de Oro' (fig. 10) (13) y Posada de San Pedro; y la 'moderna' con datación conocida, Posada de San Antonio (1878) (21). 

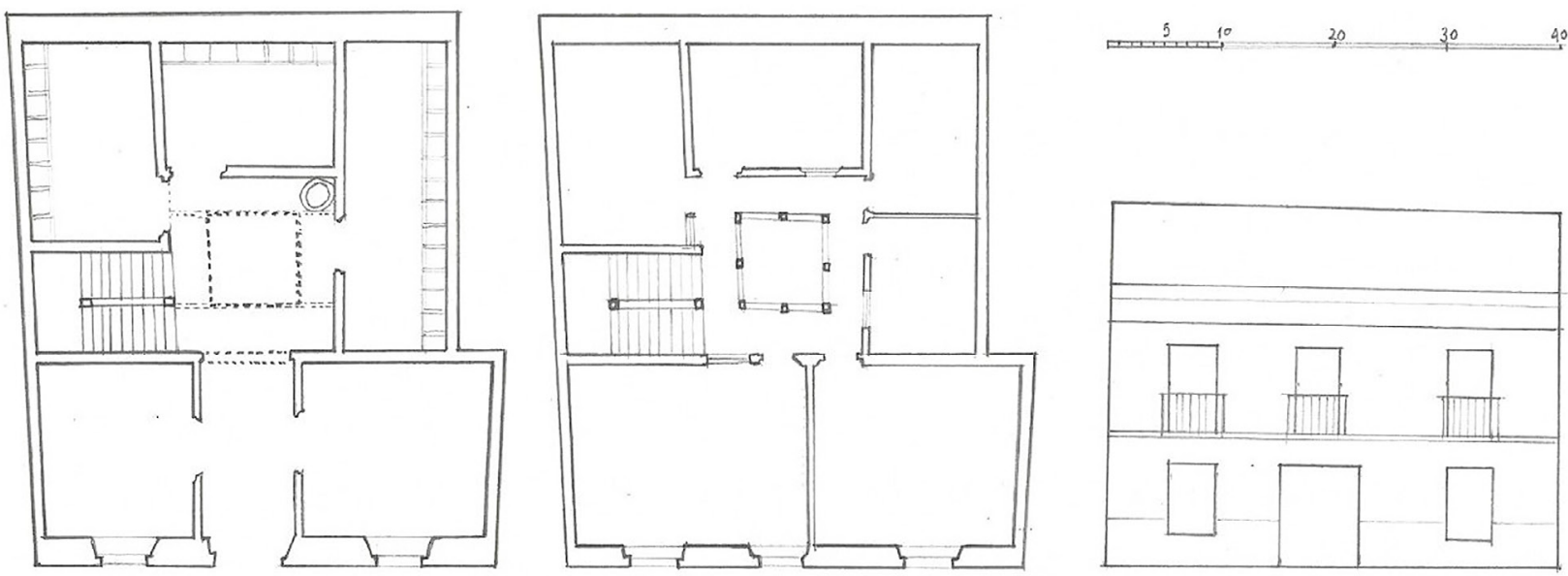

Figura 9. Posada en la Cava Baja (1724): alzado, plantas baja y principal. Planimetría a partir del expediente, AVM: 1-66-128. (E. GonzálezRedondo, 2020).
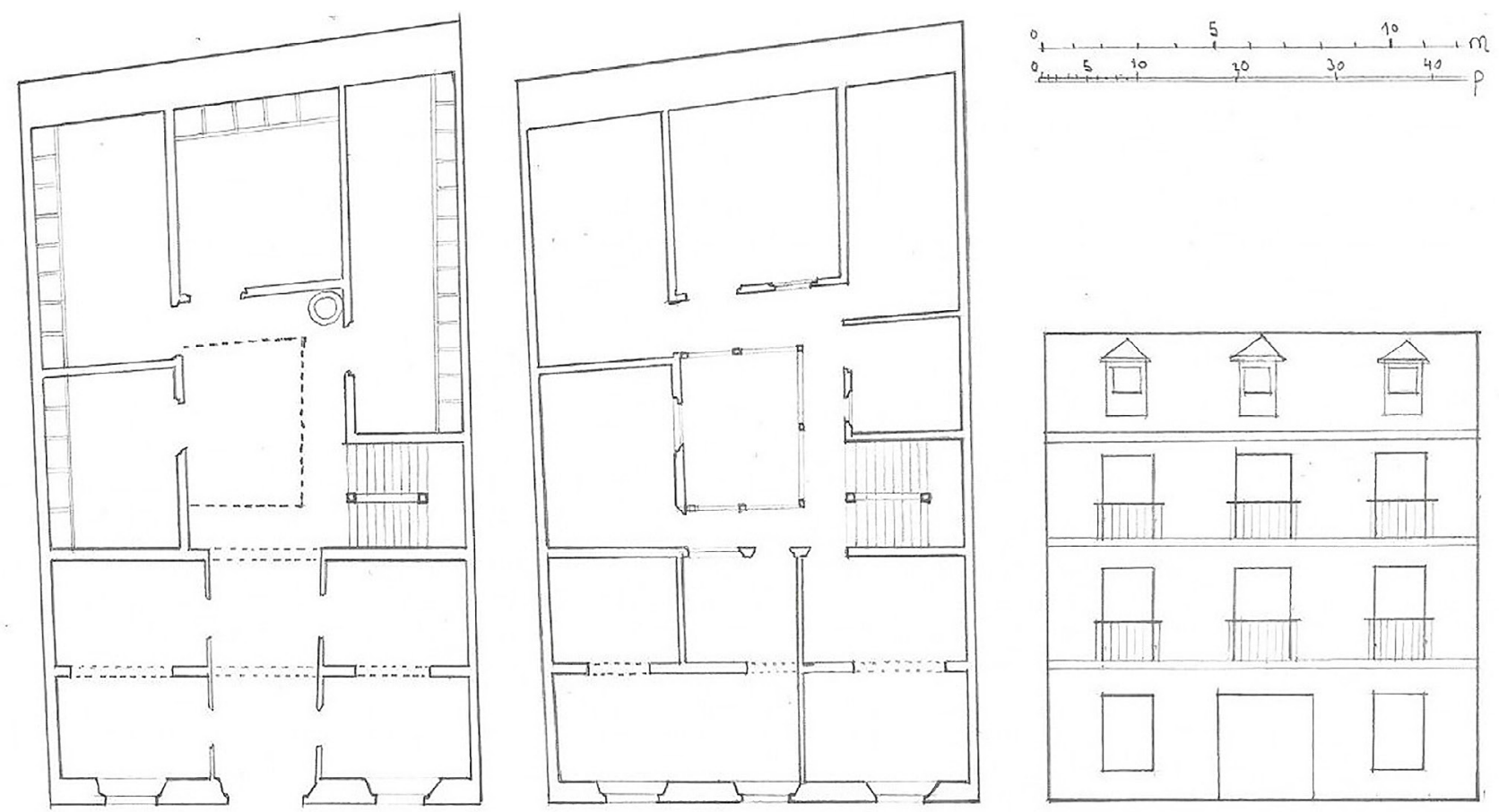

Figura 10. Posada El León de Oro (1730-50) (13): alzado, plantas baja y principal. Reconstrucción de la planimetría original a partir del edificio conservado. (E. González-Redondo, 2020).

\section{LA CASA DE TRANSICIÓN}

El avance de la investigación pone al descubierto que muchas casas particulares sencillas, que no estaban registradas, o no consta su expediente de solicitud de licencia de obras de nueva construcción (21), podían esconder otras obras en el corral. La elaboración de un nuevo Catastro en 1765 (27), cuyo objetivo era cuantificar y gravar ese aumento de edificación que no constaba en el documento inicial asociado al Texeira (1656) (fig. 4), actualizó así las rentas ocultas obtenidas por el alquiler de esos cuartos traseros escondidos. Sin embargo, ese reajuste impositivo no llevaba anexa su correspondiente descripción constructiva, lo que conduce, de este modo y por primera vez en este artículo, a la demostración de la existencia de la 'casa-patio de transición'. Esta proviene de la ampliación del sector frontal de una casa existente, generalmente 'a la malicia' (28) y nunca inscrita, y la construcción de su sector trasero con crujías adosadas a las medianeras o tapias del corral formando un patio con corredor.

\subsection{Casa con patio de transición}

Las primeras casas con un patio, resultado de la transformación y ampliación de una casa antigua para destinarla al alquiler, mantenían la planta principal como vivienda del propietario y el resto de la edificación, sector trasero, plantas superiores y desvanes, para 'cuartos de alquiler'. Los casos más antiguos documentados, Olmo (1742) y Jardines (1759) (19), dejan un patio interior sin corredor y muestran también cómo se va gestando así el primer modelo de vivienda mínima de alquiler en los desvanes con 2 piezas, sala y alcoba.

\subsection{Casa-patio de transición}

La investigación, en su objetivo por descubrir si algunos de los casos documentados de 'casas a la malicia', o casas-patio aún desconocidas, escondían cuartos de alquiler en el corral, ha localizado un caso excepcional. Se trata del expediente más 

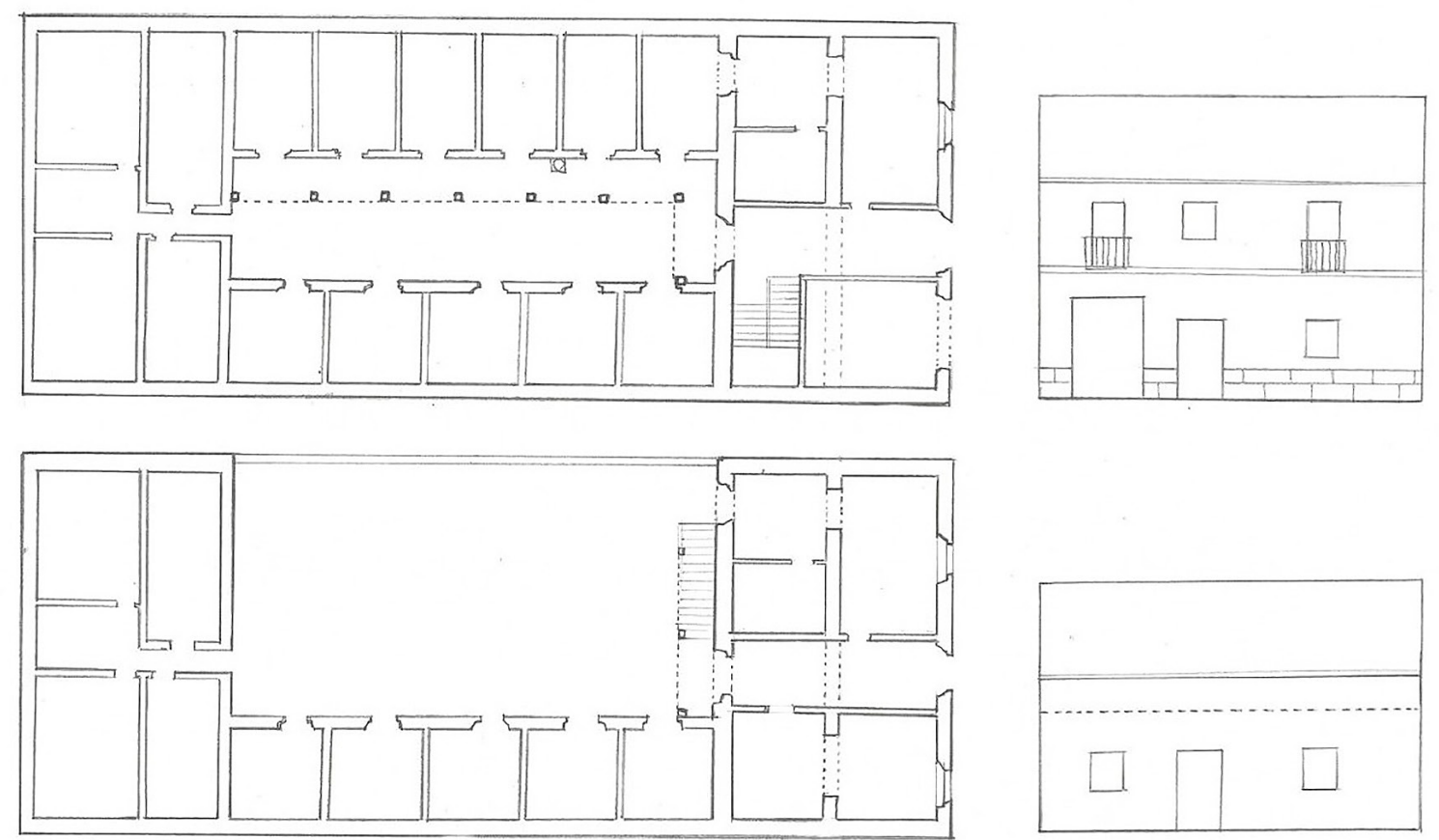

Fig. 11. Posada 'a la malicia' en c/Magdalena (1737). Hipótesis de reconstrucción de su estado original y transformación en casa-patio a partir del expediente: AHPM (16.430): a) abajo: alzado y planta original; b) arriba: conservación y reforma de las piezas antiguas, construcción de nueva crujía de 2 plantas con corredor; y reforma de la planta principal del sector frontal (E. González-Redondo, 2020).

antiguo (1737) que registra las obras de rehabilitación y ampliación de una 'casa a la malicia', que ya escondía una posada, y que además continúa ampliando la construcción trasera con nuevos cuartos adosados a la medianera aún libre (fig. 11).

Según el estudio realizado, sobre esta deteriorada casa 'a la malicia' situada en c/Magdalena (1737) (29), y conservando las paredes maestras o muros de carga de sus dos crujías existentes, se abre una puerta cochera, se reparan las salas de la planta baja y principal, y se construye la escalera. También se conservan las edificaciones de sólo una altura ubicadas en el patio. Tenía una crujía de $13 p(3.64 \mathrm{~m})$ con 5 cuartos idénticos de $11.7 \mathrm{~m} 2$, llamados 'aposentillos', y otra al fondo con varias piezas. Junto a la tapia o medianera libre se levanta una nueva edificación de 2 plantas, desde la cimentación hasta la cubierta, reduciendo la anchura inicial del patio de $30 p(8.4 \mathrm{~m})$, a sólo 9p (2.5m). Consta de una crujía de $16 \mathrm{p}(4.5 \mathrm{~m})$ con 6 nuevos cuartos de una pieza por cada planta $(12.6 \mathrm{~m} 2)$ y una galería o corredor en L, de $5 p$ (1.30m) de ancho. Se construye con basas de piedra berroqueña, entramados de tercia en pies derechos, zapatas y carreras (5), y antepechos de tabique. Es el caso más antiguo localizado con vocación de construcción en serie, resultando un total de 20 habitaciones de unos $12 \mathrm{~m}^{2}$ (fig. 11).

Además, los dos sectores, el frontal que es el original, y el trasero fruto de sucesivas ampliaciones, están diferenciados por un muro de gran espesor. Se demuestra la tesis inicial sobre la existencia de casas-patio que provienen de la transformación de casas particulares preexistentes. Este proyecto fija así los parámetros de transición: 1) la existencia de sectores estructuralmente diferenciados con un muro grueso de fachada al patio; 2) las crujías asimétricas en el sector trasero, si están construidas en fechas diferentes; 3) una puerta y zaguán amplios de acceso al patio; 4) la construcción de una nueva escalera; y 5) la repetición seriada de un módulo o solución habitacional.
Se han descubierto algunos expedientes de casas 'a la malicia' con alzados de 3 huecos $(8.4 \mathrm{~m}-12 \mathrm{~m})$, solar rectangular, 3 paredes medianeras, y que podrían esconder ejemplos similares de casas-patio de transición. La comprobación de esta información concluye que todas estaban situadas en los 'arrabales', siendo destacables: S. Antón (1767); Buenavista (1778); S. Ildefonso (1780); y Amor de Dios (1783) (21). La inexistencia de información original en planta, unido al hecho de que todas han desaparecido o están muy transformadas, dificultan de nuevo el avance de la investigación.

\section{LA CASA-PATIO COLECTIVA}

Los proyectos con información gráfica en planta de 'cuartos de alquiler', muestran mayoritariamente distribuciones de 2 viviendas por planta de grandes dimensiones. Estaban divididas en 7 o más piezas siendo singulares, Plazuela Rastro (1674), Plazuela San Felipe (1742); y Hortaleza (1760) (21). Todas ellas han desaparecido y, se localizaban en el Centro, o en calles principales. Sin embargo, se han encontrado proyectos antiguos con información rigurosa de pequeñas unidades de alojamiento en los arrabales. Entre otros, Palma c/v San Gregorio (1765); Pez c/v Corredera San Pablo (1768); Palma c/v San Andrés (1776) (21). No obstante, estos primeros casos, dada la condición de edificación en esquina, unido al escaso fondo de la parcela, hace que no exista sector trasero. A pesar de ello, se detecta que se va perfilando el modelo de vivienda-tipo en un sector frontal todavía sin una organización estructural clara, pero donde ya se incluyen viviendas con 3 piezas (sala, alcoba y cocina).

\subsection{Primeros datos constructivos en planta: el ori- gen de la vivienda mínima y su repetición 'en serie' (1745-1772)}

La documentación gráfica más antigua de casas-patio colectivas muestra solares regulares e irregulares, con alturas 
desde 1 hasta 3 , y pequeños 'cuartos de alquiler' o viviendas extendidas en toda su planta (1745-1772). Algunas se ubicaban próximas a la Cerca de Felipe II, y todas las demás en los arrabales; y aunque subsistían 100 años después de su construcción (1872-74) (fig. 6), pocas superaron los 200 años (17). El proyecto más antiguo localizado y de gran rigor en su distribución, aunque de sólo una medianera, es una casa de 2 plantas y 3 fachadas, Espada (1745) (30) (fig. 12).

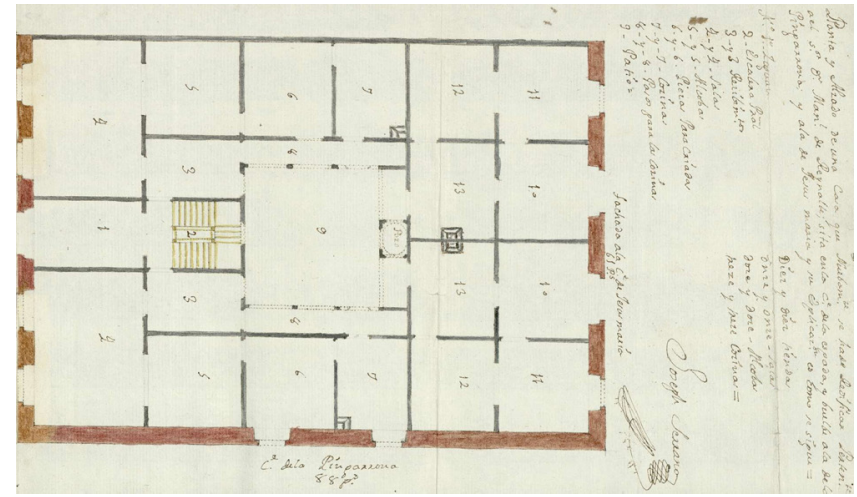

Fig. 12. Casa-patio colectiva, c/Espada (1745, AVM: 1-84-76).

Sin embargo, el modelo más puro y representativo de este estudio, al tener 3 paredes medianeras y sector trasero en O, es Greda (1748) (31). Otro caso, de reciente demolición (d.1997), es Amparo (1751), tenía dos plantas y un patio en C (fig. 5b). Fe c/v Buenavista (1751) (32), destaca por tener sólo planta baja y todas sus viviendas de 2 piezas (fig. 13); Buenavista (1751), es un caso singular por su poca definición gráfica; Cuesta San Vicente (1759) (33), es la mejor documentada, tiene grandes dimensiones, 3 corredores en $\mathrm{C}$, y un total de 34 viviendas; Escorial (1760) tiene 3 viviendas de 3 piezas por planta y una de 2; y finalmente, otras como Red de San Luis (1767), y Puebla (1768) son largas y estrechas (21) y (tabla 1).

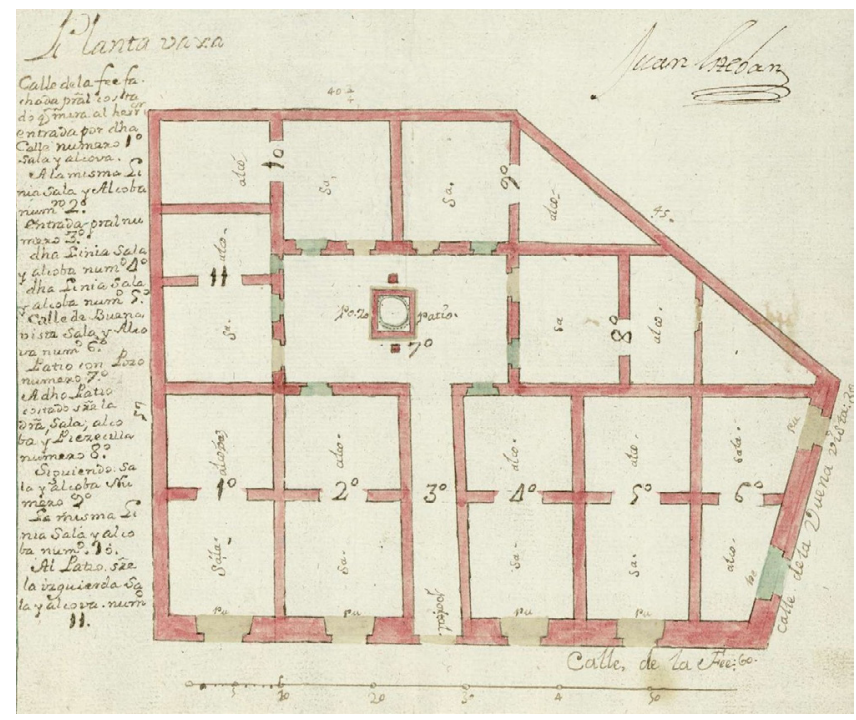

Figura 13. Casa-patio colectiva, c/Fe (1751, AVM 1-84-146).

En un sector frontal, todavía difuso y no siempre coincidente con las dos primeras crujías, se va configurando un modelo de vivienda-tipo de 4 piezas (sala, alcoba, cocina y cuarto de criados), según muestran: Espada (1745) Greda (1748) y Amparo (1751) (figs. 12, 14 y 5b). Otros casos, también sin una definición estructural clara, dibujan las viviendas a fachada con 3 piezas (sala, alcoba y cocina), Escorial (1760). Este sector frontal evoluciona hasta la ideación y repetición de un módulo habitacional, o 'cuarto de alquiler de 3 piezas' (sala, alcoba y cocina), estructuralmente delimitado por los muros de carga de las 2 primeras crujías. Por su rigor constructivo se cree que es el que terminó imponiéndose en fachada (figs. 14, 15 y 16).

En el sector trasero, accediendo por una puerta y pasillo estrechos, se sitúan viviendas de menores dimensiones con 2 piezas, sala y alcoba, (Greda, 1747; Amparo, 1751; y Fe c/v Buenavista, 1757). Todas las galerías o corredores son comunitarios y en voladizo, menos Espada (1745) (fig. 12) y Cuesta San Vicente (1759) (fig. 15). Casi todas dibujan un pozo y, excepcionalmente, algunas incluyen el vertedero (Amparo, 1751 y Cuesta San Vicente, 1759). Rara vez se dibuja la letrina de uso comunitario en el patio, como Red de San Luis (1768) (21). Esta será el precedente de las populares columnas de retretes compartidos, adosadas al corredor en todas las plantas, y construidas unos años después.

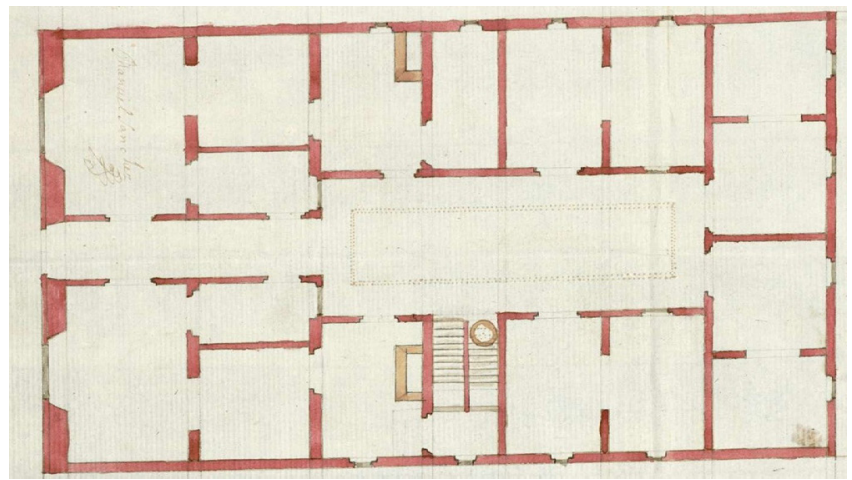

Figura 14. Casa-patio colectiva, c/Greda (1748, AVM: 1-84-106).

Surge así un proto-tipo de casa-patio colectiva cuyos elementos constructivos serán inseparables del tipo posteriormente consolidado (tabla 2):

- Una organización incipiente de los sectores frontal y trasero, con 'cuartos'-tipo a fachada y la repetición en serie de 'cuartos'-tipo alrededor del patio, también en planta baja.

- Intención de aprovechamiento máximo del solar, incluso en parcelas de pequeño tamaño o irregulares.

- Construcción de elementos compartidos: escalera, corredor, patio, pozo (figs. 14 y 15) y vertedero en las antiguas o letrinas en las modernas.

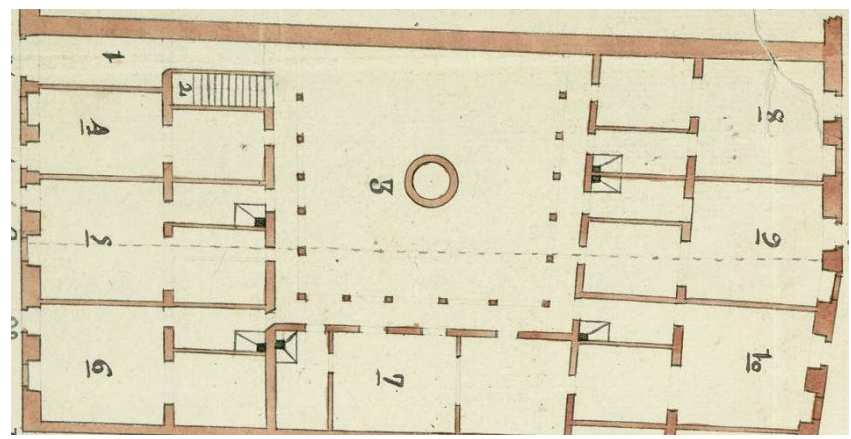

Figura 15. Casa-patio colectiva, c/ San Vicente (1759, AVM: 1-45-140).

El espesor del muro de fachada varía entre (2p-23/4p) (56$77 \mathrm{~cm}$ ); sin embargo, es llamativo que Fe (1751) (fig. 13), de sólo una altura tiene un muro de $23 / 4 \mathrm{p}(77 \mathrm{~cm}) \mathrm{y}$, por el contrario, Greda (1748), Buenavista (1751), y Cuesta San Vicente (1759), todos ellos con 3 alturas, tienen fachadas de sólo $2 p(56 \mathrm{~cm})$. 
Para los muros de carga interiores del sector frontal, en la mayor parte de los casos estudiados, tienen $1 \mathrm{p}(28 \mathrm{~cm})$. Por el contrario, en el sector trasero, los muros de carga se reducen hasta los 3/4p (21cm), aunque las luces de las crujías sean similares. En algunos casos, los muros del sector trasero son de extrema delgadez, coincidiendo con el espesor de los tabiques: Espada (1745), Amparo (1751) y Cuesta San Vicente (1759).

\section{DISCUSIÓN DE RESULTADOS}

Las casas-patio, en tanto que eran propiedad de un particular, se registraban como Construcciones particulares (21), y según su uso, podían ser: vivienda del propietario, posadas o casas con viviendas para alquilar. Originales, transformadas o rehabilitadas, terminaron destinándose al alquiler de los entonces denominados 'cuartos' divididos en distintas piezas, tanto en el sector frontal como en las crujías alrededor del patio. Las conservadas, denominadas actualmente edificios de vivienda colectiva (17), constan de unidades habitacionales de escasas dimensiones y, en muchos casos, infraviviendas. Algunas intervenciones se han visto obligadas a agruparlas reduciendo el número original para cumplir con las exigencias actuales (34).

9.1. Hacia la configuración de un modelo de nueva construcción con unidades mínimas de vivienda: 'cuartos de 1, 2 y 3 piezas' (1724-1788)

Los expedientes más antiguos de construcciones de casas (17241788) (21), aunque asociados a edificaciones desaparecidas, sitúan el origen de estas casas-patio, en la Cerca y Arrabal de Felipe II (1724); y algo más tarde, en los barrios próximos a la Cerca de Felipe IV (figs. 3, 4 y 5). Su objetivo era lograr el mayor número posible de 'cuartos' para alquilar. Atendiendo a la documentación gráfica descubierta, las Posadas trazan 'cuartos de una pieza' de pequeñas dimensiones (6-16m2), como en la Posada del Peine, 1654 (26); Posada Cava Baja, 1724 (figs. 9) y Posada en c/ Magdalena (1737) (fig. 11) y Tabla 1. En paralelo, y según estudiado en la transformación de Olmo (1742) y Jardines
(1759) (19), los primeros 'cuartos de alquiler' con 2 piezas comienzan a proyectarse en las buhardillas de las antiguas 'casas a la malicia' tras su ampliación. También se construyen en las primeras casas-patio colectivas de los arrabales (Greda, 1748; Fe, 1751; y Amparo, 1751) (figs. 5b, 13 y 14). Poco después, comienza la repetición de cuartos de 3 piezas en el sector frontal, tanto en algunas del Centro (Cuesta de San Vicente, 1759) (fig. 15), como en el Arrabal (Limón, 1767) (fig. 16).

En estas primeras casas-patio colectivas se encuentran los tipos de planta rectangular entre medianeras más habituales conservados (fig. 6). Se registran soluciones con 4 corredores o en forma de $\mathrm{O}$; con 3 galerías formando una $\mathrm{C}$ o U; en $\mathrm{L}$ o con dos corredores en ángulo recto; y con un solo corredor o forma de I (Tabla 1). Expedientes posteriores no incluyen ya la planta de los edificios, sino solo su alzado, factor este que imposibilita un avance mayor (Tabla 2). Junto a ello, no existen planos históricos anteriores a 1860 que representen la gradual construcción de los corrales dejando un patio interior. De aquí se infiere que la información original en planta finalmente encontrada (tabla 1), y descrita en este artículo (1724-1768), es excepcional.

\subsection{La consolidación de una nueva tipología cons- tructiva: la casa-patio colectiva (1777-1796)}

En un corto periodo de tiempo se construyeron las primeras fábricas de los arrabales. En el Sur, se levantaron las fábricas del Salitre (1778-1785) y la Real Fábrica de Tabacos y Aguardientes (1780-1796) (fig. 6); y en el norte, las Reales Fábricas de papeles pintados (1786); ceras (1788); y relojes (1788-1793) (fig. 3). Surgió al mismo tiempo la necesidad de construir nuevos 'cuartos de alquiler', consecuencia del incesante crecimiento de la población. La escasez de suelo libre o eriales dentro de la muralla condujo al Real Decreto de 1788, que prohibía la construcción de 'casas a la malicia' o de una planta, típicas entonces de los arrabales (28). Entre los innumerables expedientes consultados, además de las plantas mencionadas, se han estudiado numerosos alzados

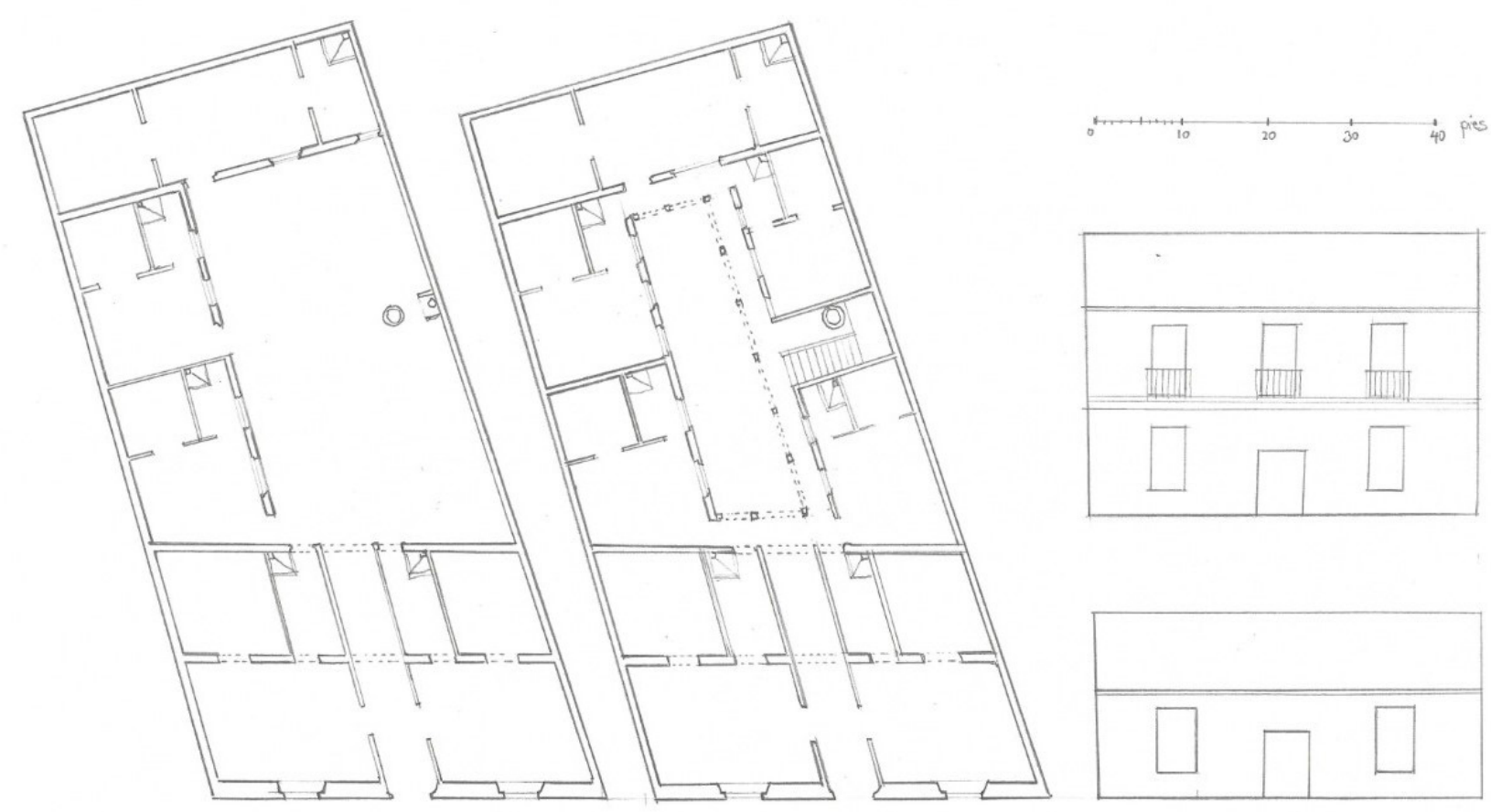

Fig. 16. Reconstrucción de Limón (1767) en el Arrabal norte: a) planta original; b) ampliación con otra nueva crujía; c) alzados: original 'a la malicia' y final con 2 alturas (E. González-Redondo, 2020). 
de casas-patio conservadas con distinta catalogación (tabla 2). En este punto, demostrar que la construcción de todo el edificio, incluidos sus patios, coincide con la fecha de construcción de su fachada es complejo (19). No obstante, los resultados del estudio concluyen que los casos edificados en los arrabales responden al modelo estudiado, y que ambos sectores, todavía de poca altura, podrían haberse construido en la fecha del expediente. Sin embargo, las casas-patio aún desconocidas, apuntan a que podrían ser el resultado de la ampliación de otras existentes, como Magdalena, 1737 (fig. 11) y Limón, 1767 (fig. 16), ambas demolidas.

\subsection{La transformación de antiguas posadas en ca- sas-patio colectivas: huellas borradas}

La persistente insuficiencia de cuartos de alquiler para alojamiento de los obreros, unido a la largamente impuesta prohibición de construir fuera de la muralla (fig. 3), llevó a los propietarios de cada casa: vivienda particular, posada, o edificio de vivienda colectiva, a construir tantos niveles como permitieran las nuevas Ordenanzas publicadas para ese fin (1847-1892). La estabilidad y calidad constructiva del edificio existente debía ser comprobada por un arquitecto antes de construir nuevos forjados, alcanzando en calles estrechas las 4 plantas y en las calles principales 5 alturas (16). También se debía mejorar el aspecto de la fachada, buscando un cierto ritmo y simetría de huecos. Por otro lado, ciertas casas-patio de 2 plantas y puerta grande no sólo modificaron sus huecos y aumentaron su altura, sino que estrecharon su acceso, Salitre 34 y Ave María 41, (figs. 17 y 18). Se cree que algunas de las conservadas pudieron ser antiguas posadas que añadieron nuevos forjados y transformaron su aspecto exterior tras las Ordenanzas.

\subsection{Los edificios de vivienda colectiva denominados Posadas}

Por otro lado, la comprobación de que algunas casas-patio conservadas tienen nombre de Posada, pero son simi-

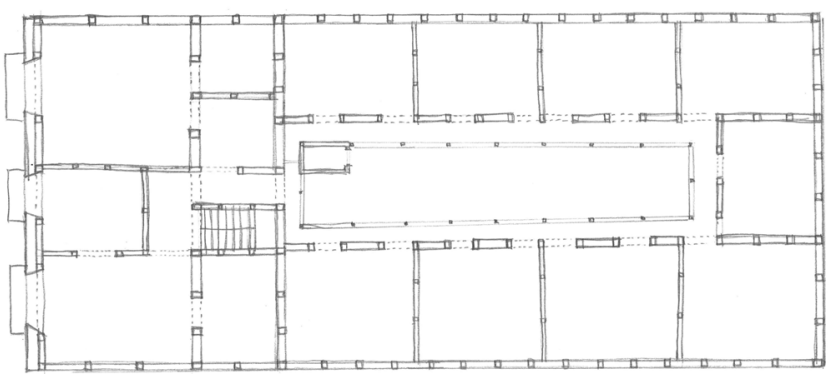

Figura 17. Casa-patio colectiva, Ave María 41, (E. González-Redondo, 2020).

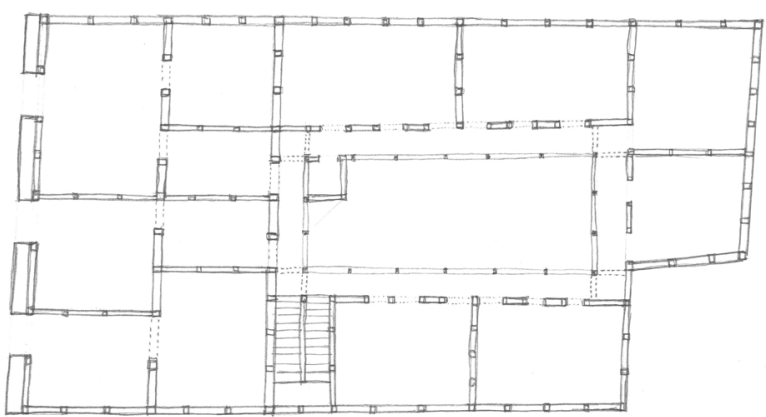

Figura 18. Casa-patio colectiva, Salitre 34, (E. González-Redondo, 2020). lares a la casa-patio colectiva aquí estudiada (Posada del Dragón, 1858; y Posada de San Antonio, 1878) (21), nos lleva a una nueva reflexión. La cuestión es determinar si finalmente se terminó utilizando el término Posada, originalmente asociado al alojamiento provisional de viajeros, para referirse también a las casas-patio colectivas para alojamiento permanente de familias. Esta tesis nos reconduce al comienzo de la investigación, donde se indicaba que el término corrala o casa de corredor es reciente. De hecho, surge al menos 200 años después de las primeras casas-patio aquí documentadas (1737-1768) (tabla 1), y 100 años después de referirse a ellas como 'casas de vecinos' (21).

Este estudio apunta a que la tesis más plausible, dado que en su origen algunas fueron Posadas, es que probablemente se terminó denominando Posada a las casas-patio de vivienda colectiva. Su demostración es compleja una vez más, puesto que en ambos tipos de casas-patio la superficie habitacional era de reducidas dimensiones. Además, los elementos que separan las habitaciones en las Posadas, o las divisiones interiores en los cuartos de alquiler, son tabiques y no muros de carga, pudiendo haberse modificado desde su construcción original. Sin duda, la tipología constructiva de casa-patio de entramado de madera se adaptaba muy bien a ambos tipos de alojamiento, y su diferencia no está clara 200 años después de su construcción. Los casos mencionados así lo demuestran, la Posada del Dragón (1858), que siempre tuvo un acceso estrecho, es actualmente un hotel; y la Posada de San Antonio (1878), que siempre tuvo un acceso muy amplio, es hoy un edificio de vivienda colectiva.

\subsection{Las 'posadas a la malicia' y los casos sin docu- mentación original}

Magdalena (1737) es la primera 'posada a la malicia' documentada y, además, tenía habitaciones en planta baja (fig. 11). Siguiendo este caso excepcional, si las casas ya tenían un nuevo sistema impositivo en base a la construcción existente en 1765, y desde 1788 las casas debían aumentar su altura para que hubiera más cuartos de alquiler, parece que 1788 podría ser el punto de inflexión de la generalización de un cambio comenzado años antes (Tabla 1). No obstante, a pesar del reconocido éxito en la datación de muchos alzados (1751-1868) (Tabla 2), aunque demolidos los más antiguos, todavía son numerosos los casos conservados, de origen desconocido, y por estudiar (35).

Estas incógnitas apuntan aquí en dos direcciones, por un lado, se considera que las casas-patio indocumentadas (fig. 17), son muy antiguas; y por otro lado, sigue abierto el estudio de la construcción del sector trasero como la gran incógnita en casi todas las que solo registran el alzado (36) (fig. 18) y Tabla 2. Con carácter general, afirmamos que, original o transformada, la casa-patio colectiva se convirtió gradualmente en el resultado de construir el mayor número posible de unidades de habitación para el alquiler, en ambos sectores, frontal, y trasero. Se basaban en la repetición de un módulo básico o vivienda de condiciones mínimas que ya se había gestado antes de 1788 (tabla 1). La solución constructiva más extendida tenía cuartos de 3 piezas en fachada, y de 2 piezas en las viviendas alrededor del patio, subdivididos después en 3 (fig. 16). 
Tabla 1. La casa-patio colectiva en Madrid (1737-1767)

\begin{tabular}{|c|c|c|c|c|c|c|c|c|c|c|c|c|c|c|c|c|}
\hline \multicolumn{3}{|c|}{ CASA-PATIO } & \multicolumn{3}{|c|}{ PARCELA } & \multicolumn{3}{|c|}{ PATIO } & \multicolumn{4}{|c|}{ CRUJÍAS } & \multicolumn{4}{|c|}{ VIVIENDAS } \\
\hline \multirow{2}{*}{$\begin{array}{l}\text { Fecha } \\
(1737) \\
\end{array}$} & \multirow{2}{*}{\begin{tabular}{|l} 
Calle \\
Magdalena
\end{tabular}} & \multirow{2}{*}{$\begin{array}{l}\text { h } \\
2\end{array}$} & \multirow{2}{*}{\begin{tabular}{|c|}
$\begin{array}{c}\text { Forma } \\
\text { patio }\end{array}$ \\
$\mathrm{L}$ \\
\end{tabular}} & \multirow{2}{*}{$\begin{array}{c}\begin{array}{c}\text { Frente } \\
\text { (m) }\end{array} \\
13.4\end{array}$} & \multirow{2}{*}{$\begin{array}{c}\text { fondo } \\
\text { (m) }\end{array}$} & \multirow{2}{*}{$\begin{array}{c}\begin{array}{c}\mathbf{A} \\
(\mathbf{m})\end{array} \\
2.5 \\
\end{array}$} & \multirow{2}{*}{$\begin{array}{c}\mathbf{L} \\
(\mathbf{m}) \\
16.2 \\
\end{array}$} & \multirow{2}{*}{$\begin{array}{c}\begin{array}{c}\text { Area } \\
\left(\mathbf{m}^{2}\right)\end{array} \\
41 \\
\end{array}$} & \multirow{2}{*}{$\begin{array}{l}\begin{array}{c}\mathbf{1}^{\mathbf{a}} \\
(\mathbf{m})\end{array} \\
4.2 \\
\end{array}$} & \multirow{2}{*}{$\begin{array}{l}\begin{array}{c}\mathbf{2}^{\mathbf{a}} \\
(\mathbf{m})\end{array} \\
3.9\end{array}$} & \multirow{2}{*}{$\begin{array}{c}\begin{array}{c}\mathbf{P} \\
(\mathbf{m})\end{array} \\
4.5\end{array}$} & \multirow{2}{*}{$\begin{array}{l}\begin{array}{c}\mathbf{F} \\
(\mathbf{m})\end{array} \\
4.2\end{array}$} & \multicolumn{2}{|c|}{$\begin{array}{l}\text { Fachada } \\
\left(\mathrm{n}^{\mathbf{0}} / \mathrm{m}^{2}\right)\end{array}$} & \multicolumn{2}{|c|}{$\begin{array}{c}\text { Patio } \\
\left(\mathrm{n}^{\mathbf{0}} / \mathbf{m}^{2}\right)\end{array}$} \\
\hline & & & & & & & & & & & & & 2 & $40-50$ & 16 & 12 \\
\hline (1745) & Espada & 2 & $\mathrm{O}$ & 17 & 23.5 & 8.2 & $7 \cdot 3$ & 60 & 3.6 & 2.8 & 3.1 & - & 8 & $33-40$ & - & - \\
\hline (1748) & Greda & 3 & $\mathrm{O}$ & 12.3 & 22.7 & 3.9 & 11 & 43 & 3.6 & 0.4 & 3.6 & 3.4 & 6 & 21-33 & 12 & $18-20$ \\
\hline$(1751)$ & $\mathrm{Fe}$ & 1 & - & 19 & 16 & 6.7 & 3.9 & 26 & 3.6 & 2.8 & 3.1 & 3.4 & 5 & $21-23$ & 4 & $17-20$ \\
\hline (1751) & Amparo & 2 & $\mathrm{C}$ & 5.2 & 19.6 & $3 \cdot 4$ & 5.9 & 20 & 4.2 & 3.1 & 2.8 & 3.4 & 2 & 36 & 4 & $12-24$ \\
\hline (1751) & S. Miguel & 2 & $\mathrm{O}$ & 19.6 & 21.8 & 8.7 & 6.4 & 56 & 4.8 & 4.2 & 3.6 & 3.9 & 3 & 48 & 12 & $12-27$ \\
\hline (1757) & Buenavista & 1 & $\mathrm{~L}$ & 12.3 & 23 & $5 \cdot 9$ & 9 & 53 & 4.5 & 4.5 & 3.6 & - & 6 & 42 & 9 & 15 \\
\hline (1759) & S. Vicente & 2 & $\mathrm{C}$ & 12.5 & - & 8.4 & 7.8 & 66 & 3.4 & 2.8 & 2.5 & - & 33 & 22 & 1 & 21 \\
\hline$(1760)$ & Escorial & 3 & I & 10.6 & 18.8 & 3.6 & 4.5 & 16 & 3.6 & 3.4 & 3.9 & - & 6 & 36 & 6 & $15-28$ \\
\hline (1762) & St. Brígida & 2 & I & 7.6 & 35.6 & 1.4 & 18.2 & 26 & 4.2 & $3 \cdot 4$ & 3.1 & 2.2 & 2 & 45 & 6 & 16 \\
\hline$(1767)$ & Limón & 1 & $\mathrm{O}$ & 13 & 23.8 & 6.7 & 12.6 & 85 & 3.9 & 3.4 & 3.9 & 3.4 & 2 & 42 & 3 & 22-35 \\
\hline
\end{tabular}

Tabla 2. Casas-patio colectivas construidas en la c/ Salitre (1772-1898). P (protección parcial); (F/P/E) (fachada, patio, escalera); A (ático); B (buhardillas). Forma del patio (O: 4 corredores; U: 3 corredores; L: 2 corredores; I: 1 corredor)

\begin{tabular}{|c|c|c|c|c|c|c|c|c|c|c|}
\hline \multicolumn{11}{|c|}{ CASAS-PATIO CONSTRUIDAS EN C/ SALITRE (1772-1898) } \\
\hline \multirow{4}{*}{$\begin{array}{c}\begin{array}{c}\text { DATOS } \\
\text { (AVM) }\end{array} \\
\text { Fecha }\end{array}$} & \multirow{2}{*}{\multicolumn{3}{|c|}{$\begin{array}{l}\text { TOMA DE DATOS } \\
\text { 'in situ' }\end{array}$}} & \multirow{2}{*}{\multicolumn{2}{|c|}{$\begin{array}{c}\text { ALZADO } \\
\text { Altura }\end{array}$}} & \multicolumn{5}{|c|}{ PLANTA } \\
\hline & & & & & & \multirow{2}{*}{\multicolumn{2}{|c|}{$\begin{array}{c}\text { Solar } \\
\text { Area }\end{array}$}} & \multicolumn{2}{|c|}{ Patio } & \multirow{3}{*}{$\frac{P / S}{\%}$} \\
\hline & \multirow{2}{*}{$\mathrm{n}^{\mathbf{o}}$} & \multirow{2}{*}{ (PGOUM) } & \multirow{2}{*}{ Forma } & \multirow{2}{*}{ Original } & \multirow{2}{*}{ Actual } & & & \multirow{2}{*}{$\begin{array}{l}\text { Ancho } \\
\text { A (m) }\end{array}$} & \multirow{2}{*}{$\begin{array}{l}\text { largo } \\
1(\mathrm{~m})\end{array}$} & \\
\hline & & & & & & $\mathbf{A}(\mathbf{m})$ & $\mathbf{L}(\mathbf{m})$ & & & \\
\hline 1772 & 38 & - & $\mathrm{O}$ & $2+B$ & - & - & - & - & - & - \\
\hline 1777 & 34 & $\mathrm{P}(\mathrm{F} / \mathrm{P})$ & $\mathrm{O}$ & $2+B$ & $3+\mathrm{A}(1851)$ & 13.5 & 24.4 & 3.9 & 10.2 & 12.1 \\
\hline 1778 & 14 & - & - & $2+B$ & - & - & - & - & - & - \\
\hline 1781 & 56 & - & - & $2+B$ & $3(1791)$ & - & - & - & - & - \\
\hline 1788 & 44 & $\mathrm{~A}(\mathrm{~F})$ & $\mathrm{L}$ & $2+B$ & $4(1854)$ & 7.1 & 23.1 & & & \\
\hline 1788 & 32 & $P(F / P / E)$ & $\mathrm{O}$ & $3+B$ & 3 & 14.3 & $25 \cdot 3$ & 4.7 & 8.9 & 11.6 \\
\hline 1790 & 36 & $\mathrm{P}(\mathrm{F} / \mathrm{P} / \mathrm{E})$ & I & $2+B$ & $3+\mathrm{A}(1851)$ & 7.2 & 24.2 & 2.1 & 10.3 & 12.4 \\
\hline 1791 & 54 & $\mathrm{P}(\mathrm{F} / \mathrm{P})$ & $\mathrm{L}$ & $3+B$ & $3+\mathrm{B}$ & 6.5 & 23.1 & 3.0 & 6.1 & 11.9 \\
\hline 1794 & 25 & $\mathrm{P}(\mathrm{F} / \mathrm{P} / \mathrm{E})$ & I & $3+B$ & $3+B$ & 76 & 23.1 & 2.1 & 8.1 & 9.7 \\
\hline 1831 & 28 & $\mathrm{P}(\mathrm{F} / \mathrm{P} / \mathrm{E})$ & $\mathrm{C}$ & 4 & 4 & 10.3 & 25.4 & 1.7 & 5.7 & 3.2 \\
\hline 1831 & 30 & $\mathrm{P}(\mathrm{F})$ & $\mathrm{L}$ & 4 & 4 & 7.8 & 24.8 & 2.2 & 5.5 & 6.2 \\
\hline 1832 & 42 & $\mathrm{P}(\mathrm{F} / \mathrm{P} / \mathrm{E})$ & $\mathrm{L}$ & $3+B$ & $3+\mathrm{B}$ & 8.8 & 22.2 & 3.2 & 6.9 & 11.3 \\
\hline 1864 & 48 & $\mathrm{P}(\mathrm{F} / \mathrm{P} / \mathrm{E})$ & $\mathrm{O}$ & 4 & 4 & 14.9 & 24.1 & 3.7 & 9.8 & 10.1 \\
\hline 1898 & 58 & $\mathrm{P}(\mathrm{F} / \mathrm{P} / \mathrm{E})$ & $\mathrm{O}$ & 3 & 3 & 13.7 & 21.8 & 4.1 & 11.4 & 15.6 \\
\hline- & 18 & $\mathrm{P}(\mathrm{F} / \mathrm{P} / \mathrm{E})$ & $\mathrm{I}$ & - & 4 & 7.6 & $25 \cdot 3$ & 3.3 & 3.5 & 6.4 \\
\hline- & 24 & $\mathrm{P}(\mathrm{F} / \mathrm{P} / \mathrm{E})$ & $\mathrm{U}$ & - & 4 & 12.2 & 14.7 & 2.9 & 6.7 & 10.1 \\
\hline
\end{tabular}

\section{CONCLUSIONES}

Se han establecido las diferencias constructivas entre los conceptos 'casa con patio' y 'casa-patio', y los distintos tipos de alojamiento: habitaciones en torno a un patio en la Posada; y cuartos para familias en la casa-patio colectiva. El análisis constructivo de proyectos originales (tablas 1 y 2) y el levantamiento planimétrico de casos singulares (figs. $9,10,11,16,17$ y 18), ha determinado la organización constructiva de los sectores y el dimensionado de los elementos estructurales. La determinación de la Cronología de los casos documentados y su relación con la Real Provisión de
1788 sitúa la transformación de algunas posadas próximas a las fábricas en un nuevo tipo de hospedaje, la casa-patio colectiva.

Se descubre por primera vez, la documentación original de un nuevo modelo de casa-patio, o ‘casa de transición' resultado de la ampliación y rehabilitación de una construcción existente. Tiene sectores estructuralmente diferenciados, corredor exterior y crujías asimétricas. El excepcional expediente de Magdalena (1737), que ocultaba una 'posada a la malicia', fija el inicio más antiguo de la repetición de un módulo habitacional. Esta casa no sólo escondía una segun- 
da planta en la segunda crujía, sino también nuevas crujías con 'aposentillos' adosadas a las medianeras en el corral. Se considera precursora del extendido arquetipo de casa-patio colectiva con cuartos de alquiler, denominado posteriormente casa de vecinos (21) y (37), y recientemente casa de corredor o corrala.

\section{FINANCIACIÓN}

CCG 19/AH-025 y CCG20/o38. Proyectos financiados por la Universidad de Alcalá, Madrid (Spain).

\section{REFERENCIAS}

(1) Pfeifer, G., Brauneck, P. (2007). Courtyard houses: a housing typology. Vol. 1. Walter de Gruyter.

(2) Urbina M. (2002). Los conventillos de Valparaíso, 1880-1920. Revista de Urbanismo 5. Doi: https://revistaurbanismo. uchile.cl/index.php/RU/article/view/12953

(3) Natera, J. (2015). Viviendas colectivas para sectores de población de bajos recursos: los inquilinatos. BAETICA, 18:223-241.

(4) Tovar, V. (1983). Arquitectura madrileña del s. XVII: datos para su estudio. Instituto de estudios madrileños, CSIC.

(5) González-Redondo, E. (2015). A timber-framed construction system preserved: The Historic Centre of Madrid. Journal of Architectural Conservation. Taylor and Francis, Vol. 21, nº 2. https://doi.org/10.1080/13556207.2015.1112125

(6) Ardemans, T. (1719). Declaración y extensión de las Ordenanzas que escribió Juan de Torija. Madrid.

(7) Marcos y Bausá, R. (1879). Manual del albañil. Dirección y Administración. Madrid.

(8) Ger y Lóbez, F. (1898). Tratado de construcción civil. La Minerva Extremeña, Badajoz.

(9) Gaztelu, L. (1899). Pequeña Enciclopedia práctica de construcción. Carpintería de armar. Bailly-Bailliere e Hijos, Madrid.

(10) Díaz, J. (1977). Las corralas de Madrid. Boden, $\mathrm{n}^{0} 13,28-49$.

(11) Sánchez, M. (1979). Vivir en una corrala. Narria: estudios de artes y costumbres populares. Vol.13, 3-8.

(12) Berlinches, A. (2003). Arquitectura de Madrid. Casco histórico, tomo I. Colegio Oficial de Arquitectos de Madrid.

(13) Santa Cruz, J., del Río, M. (2012). Estudio tipológico, constructivo y estructural de las casas de corredor en Madrid. UPM. http://oa.upm.es/14326

(14) Fernández, R., Santa Cruz, J., Río, M. (2016). Caracterización tipológica de las casas de corredor, el caso de las ciudades del casco histórico de la Habana y las corralas madrileñas. Informes de la construcción. https://doi.org/10.3989/ ic. 15.036

(15) González-Redondo, E. (2018). Historic timber framed courtyard houses: origin and development of the corralas in Madrid. Building knowledge, constructing histories, vol. 1, 683-689. https://doi.org/10.1201/9780429506208

(16) González-Redondo, E. (2020). Building and repairing historic timber-framed courtyard houses: 'corralas' in Madrid. Journal of Architectural Conservation, Taylor and Francis. https://doi.org/10.1080/13556207.2020.1735089

(17) Ayuntamiento de Madrid. (1997). Plan General de Ordenación Urbana de Madrid. Catálogo de elementos protegidos.

(18) Nueva Ordenanza Conservación, Rehabilitación y estado ruinoso de las edificaciones, ANM/65. Madrid. 6580, 27/12/2011.

(19) González-Redondo, E.(2020). Las 'casas a la malicia' y su transformación en edificios de entramado de madera 'modernos' (1656-1868): construcciones originales versus estructuras añadidas. Informes de la construcción vol. 72, 559, https://doi.org/10.3989/ic.74057

(20) Proyecto OTT/Mooo31501, (2000-2004); Proyecto (2014-2020). Universidad de Alcalá.

(21) Archivo Villa de Madrid. Obras particulares. Licencias para construcciones, Tomo 51. (1493-1795); Tomo 52 (17961843).

(22) Archivo Villa de Madrid, AVM (1-66-109), (1694). Solicitud de licencia de obras en una casa en c/Gobernador.

(23) Archivo Villa de Madrid, AVM (1-84-148), (1751). Solicitud de licencia de obras en una casa en c/Amparo.

(24) Archivo Villa de Madrid, AVM (1-47-18), (1768). Solicitud de licencia de obras en la casa existente en c/Infantas.

(25) Archivo Villa de Madrid, AVM (1-46-76), (1771). Solicitud de licencia de obras en una casa en c/Infantas.

(26) González-Redondo, E. (2019). Los primeros entramados de madera y muros de doble hoja: Posadas en Madrid (16691798). Informes de la construcción, 71,556 , e315. https://doi.org/10.3989/ic.66687

(27) Miranda, M., Fernández, M. (1765). Modo de hacer la visita de todas las casas de la Corte. Biblioteca Nacional.

(28) Corral, J. (1982). Las composiciones de Aposento y las casas a la malicia. Instituto de Estudios Madrileños, CSIC.

(29) Archivo Histórico de Protocolos de Madrid, AHPM (16.430), (1737). Obras en la casa sita en c/Magdalena.

(30) Archivo Villa de Madrid, AVM (1-84-76). (1745). Solicitud de licencia de obras en una casa en c/Espada.

(31) Archivo Villa de Madrid, AVM (1-84-106). (1748). Solicitud de licencia de obras en una casa en c/Greda.

(32) Archivo Villa de Madrid, AVM (1-84-146). (1751). Solicitud de licencia de obras en una casa en c/Fe c/v Buenavista.

(33) Archivo Villa de Madrid, AVM (1-45-140). (1759). Solicitud de licencia de obras en una casa en la Cuesta de San Vicente.

(34) Empresa Municipal de la Vivienda (2006). Rehabilitaciones EMV (2001-2006). Ayuntamiento de Madrid.

(35) Cruz, H., Yeomans, E.; Touza, M., Mannucci, M., Lorenzo, P. (2013). Guideline for on-site Assessment of Historic Timber Structures. International Journal of Architectural Heritage 9(3):277-289. https://doi.org/10.1080/15583058.20 13.774070

(36) Debailleux, L. (2015). Indexing System for recognizing Traditional Timber Framed Structures. International Journal of Architectural Heritage 9(5):529-541. https://doi.org/10.1080/15583058.2013.824045

(37) Collado, N., Matamoros, M. (2015). Las casas de vecindad. Arquitectura y Urbanismo 36(3). https://www.redalyc.org/ articulo.oa? $\mathrm{id}=376841788008$ 